\title{
Rapid Detection of Defects in Fuel-Cell Electrodes using Infrared Reactive-Flow-Through Technique
}

\author{
Andrew M. Herring, ${ }^{3}$ and Michael J. Ulsh ${ }^{2, *}$ \\ ${ }^{1}$ Environmental Energy Technologies Division \\ Lawrence Berkeley National Laboratory \\ Berkeley, CA 94720, USA \\ ${ }^{2}$ National Renewable Energy Laboratory \\ Golden, CO 80401, USA \\ ${ }^{3}$ Department of Chemical and Biological Engineering \\ Colorado School of Mines \\ Golden, CO 80401, USA
}

Prodip K. Das, ${ }^{1}$ Adam Z. Weber, ${ }^{1}$ Guido Bender, ${ }^{2}$ Austin Manak, ${ }^{2}$ Daniel Bittinat, ${ }^{2}$

\begin{abstract}
As fuel cells become more prominent, new manufacturing and production methods will need to be developed to deal efficiently and effectively with increased demand. One necessary component of this industrial growth is accurate measurement of the variability in the manufacturing process. In this study, we present a diagnostic system that combines infrared thermography with a reactive-flow-through technique to detect catalyst-loading defects in fuelcell gas-diffusion electrodes accurately with high spatial and temporal resolutions. Experimental results are compared with model predictions of thermal response with good agreement. Data analysis, operating-condition impacts, and detection limits are explored using both experiments and simulation. Overall, the results demonstrate the potential of this technique to measure defects on the millimeter length scale with temporal resolutions appropriate for use on a web-line. Thus we present the first development stage of a next-generation non-destructive diagnostic tool, which may be amenable to eventual use on roll-to-roll manufacturing lines.
\end{abstract}

Keywords: Catalyst layer, Defect detection, Infrared thermography, Fuel cells, Manufacturing

* Corresponding author: Email: michael.ulsh@nrel.gov, Phone: (303) 275-3842 


\section{INTRODUCTION}

Proton-exchange-membrane fuel cells (PEMFCs) are considered a potential key zero-emission energy-conversion technology of the $21^{\text {st }}$ century [1]. PEMFC systems are currently being deployed in some early markets, and as this commercialization expands, there must be a transition from low-volume, largely manual manufacturing methods, to high-volume, continuous and automated processes. In parallel with this transition to high-volume-manufacturing methods, there must be an effort to evaluate and develop quality-control techniques that are rapid, noncontact, and non-destructive, and which can be implemented in continuous or automated production lines. Scalable quality-control methods are especially needed for membraneelectrode-assembly (MEA) components [2], including membranes, electrodes, and gas-diffusion media (GDM), which are in many cases inspected visually before use in a stack. Of particular importance, given the high cost of platinum and other noble-metal constituents, is the detection of variations in catalyst layers (CLs). CL thickness variations, such as a spot with excessive or limited loading, can yield performance losses beyond those expected from the platinum (Pt) variation or the composition of the CL alone, especially at the local area near the defect [3-8]. This could be due to uneven compression of the GDM at the location of the defect, causing an increase in serial resistance or impedance (e.g., contact losses) and leading to water-management (e.g., flooding at the interface) and/or other issues, such as cell-performance reduction $[3,5,9]$. In addition, such variations could lead to initiation sites for membrane and other cell degradation and failure [10].

MEAs for PEMFCs are typically fabricated using roll-to-roll processes, wherein a sheet of material that is continuously formed by coating, casting, or other methods, is conveyed through 
required process steps by a roller system, with the final product wound into a continuous roll. Therefore, maintaining the quality of the final product is challenging. For in-line inspection, the fuel-cell industry is dependent on the optical inspection of visible defects or point measurements of coating thickness. While these measurements can be extremely useful, they will ultimately not be the best solution for continuous production of PEMFC MEA components. First, not all defects are visible, particularly relative to the typically black, non-reflecting electrode coatings and GDM. Second, point measurements only provide representative statistical data - they cannot generally locate discrete defects, even if scanned across the sheet of material being fabricated, as is often done in the industry. Given that discrete defects can act as failure-initiation points for MEAs in operation [11], it is critical to develop an inspection technique that measures every location on the sheet material such that defects in MEA components can be removed prior to assembly into complete cells with minimal scrap. This $100 \%$ inspection requirement is necessary to avoid premature cell failures, which often can cascade and cause complete cell and stack failure; therefore necessitating expensive replacements. In addition, the time required for the detection of defects is a key metric for any technique that is required to be on-line in a manufacturing process [2].

For CL defects, X-ray Fluorescence (XRF) spectroscopy has recently been applied for the in-line measurement of catalyst loading [12, 13]. Unfortunately, this technique cannot at this time provide $100 \%$ inspection for CL defects. Acquisition times provided by commercially available systems that provide quantitative analysis of Pt loading are such that, for a roll width of 18 in. and a web-speed of $30 \mathrm{ft} \mathrm{min}^{-1}$, data is only gathered on less than $1 \%$ of the sample area. Therefore, this technique can only provide a statistical metric of Pt loading for a given 
production run. One way around this could be a multi-pass system through the XRF, but this would slow the web speed and add complexity. Another option is to use multiple XRF setups, but this is cost prohibitive. In summary, XRF spectroscopy is an established diagnostic technique, but it has limitations relative to use as a diagnostic tool for continuous production of PEMFC electrodes.

Infrared (IR) thermography may allow for complete, rapid (with response times on the order of one second for large areas), non-contact, and non-destructive detection of defects. Several patents mention using IR thermography for detection of various PEMFC parameters, including MEA and membrane defects [14-16]. However, little public information is available on the ability of specific excitation techniques that allow for the detection of specific (size and type) defects in PEMFC materials. Recently, we have demonstrated an IR thermography and directcurrent (DC) electronic-excitation method to detect variations in CL thicknesses on decals or membranes, i.e., electrically insulating substrates, with high spatial and temporal resolution [17]. Although IR thermography techniques may not be element specific (as is XRF), our work shows that the IR-DC technique can be used to identify CL-thickness variations rapidly, at a relatively low cost, while providing $100 \%$ inspection.

In this paper, we examine an IR thermography-reactive flow through (RFT) technique that is applicable to gas-diffusion electrodes (GDEs), i.e., a CL coated on the microporous layer (MPL) of an electrically conductive gas diffusion layer (GDL). IR-RFT detects variations in Pt loadings, which, in this study, is identical to variations in CL thickness. As an initial study in the use of IR detection with reactive flow-through for CL defects, this work focuses on detecting square spots 
of different thickness in a surrounding layer of nominal thickness. Mathematical modeling is used to explore the effects of various process and material parameters.

The outline of this paper is as follows. First, the experiment, theory, and model for the technique are described. Second, the results of IR measurements with defined defects are presented and used for model validation. Third, both experiments and model are used to examine the impact of different variables of the technique including gas-mixture concentration, flowrate, defect size, and aspect ratio. Finally, the extension and applicability of this technique on a web-line, including simulating a slot flow rather than a uniform excitation, is discussed.

\section{EXPERIMENTAL}

IR-RFT was employed to detect variations of catalyst (i.e., Pt) loading in GDEs. The RFT technique involves the flow of a dilute non-flammable $\mathrm{H}_{2} / \mathrm{O}_{2}$ gas-mixture through the GDE where reaction occurs at the Pt catalytic sites in the CL. For the experiments, a flow of 0.4/0.2\% $\mathrm{H}_{2} / \mathrm{O}_{2}$ gas in $\mathrm{N}_{2}$ balance was introduced into an inlet manifold of a bench-top hardware, then passed through the gas-diffusion electrode, and finally exited through an outlet manifold as shown in Figure 1(a). The heat signature of the reaction at the electrode was captured through an IR transmitting material (POLY IR ${ }^{\circledR}$, Fresnel Technologies) using an IR camera (Jenoptik VarioCam HiRes camera) with a $640 \times 480$ pixel detector with an accuracy of under $\pm 1.5 \mathrm{~K}$. A uniform emissivity of 0.95 was used for the GDE. This value was determined empirically by comparing a piece of $3 \mathrm{M}^{\mathrm{TM}}$ brand masking tape, which has a known emissivity of 0.95 [18], at the same ambient conditions as the CL. 
CL samples with and without defects were prepared in-house from a catalyst ink containing 20 wt\% Nafion solution with 1100 EW (Ion Power, DE2020), n-propanol, water, and 46 wt\% Pt/carbon catalyst (TKK, TEC10E50E). The ionomer to carbon mass ratio was adjusted to 0.8:1 and mixing was performed overnight using a vial, zirconium oxide beads, and a ball mill. The resulting catalyst ink was then sprayed onto sheets of the commercially available GDL material BC25 from SGL, using a home-built ultrasonic spray system with a Sono-Tek Impact spray head. The spray system included a syringe pump, a $120 \mathrm{kHz}$ micro-bore spray head and power system, and a programmable $x-y$ stage. The flowrate of the catalyst ink during spraying and the speed of the sample holder were adjusted to achieve a platinum loading of $0.025 \mathrm{mg} / \mathrm{cm}^{2}$ in a single coat. During spraying, the temperature of the sample holder was controlled to $80^{\circ} \mathrm{C}$. No additional time for drying was needed between coats.

Defects with $50 \%$ and $100 \%$ loading reduction were intentionally introduced to select samples by placing stainless steel masks of either 0.25 or $2 \mathrm{~cm}^{2}$ on the GDL material for part of the spray process. The resulting loading reduction of the defect was controllable by the number of spray coats the mask was kept in place. For a loading reduction of $50 \%$, for example, the mask was removed after half the spray coats were completed, for a loading reduction of $100 \%$ the mask was kept in place during all the spray coats. After spraying, the GDL sheet was cut into individual sample pieces, ensuring that all defects were centered on the sample.

The bench-top experimental hardware of the RFT technique and an optical image of a GDE with a square defect in the center are shown in Figure 1 (a) and (b), respectively. The defect is 
highlighted by a dashed rectangle because the contrast between the black CL and the black MPL made the defect difficult to see by eye.

\section{MODEL}

To guide the experiments, improve understanding of the experimental data, and explore the technique, mathematical models of the test setup were developed. Figure 2(a) depicts the experimental setup and Figure 2(b) shows the full computational domain. The computational domain is identical to the electrode sample used in the experiments, with the exception of the brass manifolds shown in Figure 1(a).

\section{$\underline{3.1 \text { Governing equations }}$}

The general energy-balance equation used in the model to find the temperature, $T$, in the porous GDL, MPL, and CL is

$$
\left(\rho C_{p}\right)_{\mathrm{eq}} \frac{\partial T}{\partial t}+\rho C_{p} \mathbf{u} \cdot \nabla T=\nabla \cdot\left(k_{\mathrm{eq}} \nabla T\right)+Q
$$

where $\rho$ is the gas-mixture density, $C_{p}$ is the gas-mixture specific heat capacity at constant

pressure, $\left(\rho C_{p}\right)_{\text {eq }}$ is the equivalent volumetric heat capacity at constant pressure, $T$ is the temperature, $\mathbf{u}$ is the superficial mass-averaged gas-mixture velocity, $k_{\mathrm{eq}}$ is the equivalent thermal conductivity, and $Q$ is the heat generation due to the chemical reaction of $\mathrm{O}_{2}$ and $\mathrm{H}_{2}$ on Pt. 
The equivalent thermal conductivity of the porous matrix/gas mixture system, $k_{\mathrm{eq}}$, is related to the effective conductivity of the porous layer (GDL, MPL, or CL), $k_{p}^{\text {eff }}$, and to the conductivity of the gas-mixture, $k_{f}$, by

$$
k_{\mathrm{eq}}=(1-\varepsilon) k_{p}^{\mathrm{eff}}+\varepsilon k_{f}
$$

where $\varepsilon$ is the porosity of the porous layer. The effective thermal conductivity of the porous GDL, MPL, and CL are estimated using a Bruggeman correction as it provides a good approximation of the effective conductivity [19]. The equivalent volumetric heat capacity of the porous matrix/gas mixture system is calculated by

$$
\left(\rho C_{p}\right)_{\mathrm{eq}}=(1-\varepsilon)\left(\rho C_{p}\right)_{p}+\varepsilon\left(\rho C_{p}\right)_{g}
$$

where the subscripts $p$ and $g$ represent the solid-matrix of porous layer and the gas-mixture, respectively. The gas-mixture contains hydrogen, oxygen, and nitrogen. Therefore, the gasmixture density, specific heat capacity, and thermal conductivity are estimated assuming idealgas properties by

$$
\begin{gathered}
\rho=\frac{p}{R T} \sum_{i} x_{i} M_{i} \\
C_{p}=\sum_{i} \omega_{i} C_{p_{i}}
\end{gathered}
$$

and

$$
k_{f}=\sum_{i} x_{i} k_{i}
$$

respectively, where $R$ is the ideal-gas constant, and $x_{i}, \omega_{\mathrm{i}}, M_{i}$, and $k_{i}$ are the mole fraction, mass fraction, molecular weight, and thermal conductivity of species $i$, respectively. It is worth to note that the gas-mixture's specific heat capacity is estimated using the mass-weighted-mixing-law and the thermal conductivity is estimated using a simplified molar-weighting approach. 
The heat generation term is described by the reaction of hydrogen as

$$
Q=R_{r} h_{\mathrm{comb}}
$$

where $R_{r}$ is reaction rate and $h_{\text {comb }}$ is the lower heating value of hydrogen (119.96 $\left.\mathrm{MJ} \mathrm{kg}^{-1}\right)$. The reaction rate is described with the one-step mechanisms of Mitani and Williams [20]:

$$
R_{r}=A_{v} B C_{\mathrm{H}_{2}} \exp \left(-\frac{E}{R T}\right)
$$

with $B=1.4 \times 10^{3} \mathrm{~cm} \mathrm{~s}^{-1}$ and $E=14.9 \times 10^{3} \mathrm{~J} \mathrm{~mol}^{-1}$. Here $A_{v}$ is a fitting parameter to account for interfacial surface area to volume ratio.

The gas-mixture transport through the porous GDL, MPL, and CL is subject to the following mass-conservation equation, which incorporates Darcy's law for flow in the porous media,

$$
\frac{\partial}{\partial t}(\varepsilon \rho)+\nabla \cdot\left(-\frac{\rho \kappa}{\mu} \nabla p\right)=q_{m}
$$

where $\rho, \mu, \kappa$, and $p$ are the density, dynamic viscosity, permeability, and pressure, respectively. The right side of above equation is the source term that accounts for mass change due to the cell reaction and is nonzero only in the CL. The species transport through the porous GDL, MPL, and $\mathrm{CL}$ is modeled using the mixture-averaged diffusion model and the species mass transport equation is defined as

$$
\frac{\partial}{\partial t}\left(\rho \omega_{i}\right)+\nabla \cdot\left(\rho \omega_{i} \mathbf{u}\right)=-\nabla \cdot J_{m d, i}+R_{i}
$$

where $J_{m d, i}$ is the mass flux relative to the mass-averaged velocity, and $R_{i}$ is the rate expression describing the production or consumption of species $i$.

The relative mass flux due to molecular diffusion is governed by a Fick's law expression, 


$$
J_{m d, i}=-\left(\rho D_{i}^{m} \nabla \omega_{i}+\rho \frac{\omega_{i}}{M} D_{i}^{m} \nabla M\right)
$$

where $D_{i}^{m}$ is the mixture-averaged diffusion coefficient and $M$ is the mean molecular weight of the mixture. The molecular weight of the mixture and the mixture-averaged diffusion coefficient are given by

$$
M=\left(\sum_{i} \frac{\omega_{i}}{M_{i}}\right)^{-1}
$$

and

$$
D_{i}^{m}=\frac{1-\omega_{i}}{\sum_{k \neq i}^{N} \frac{x_{k}}{D_{i k}}}
$$

respectively, where $M_{i}$ is molecular weight of species $i, x_{k}$ the mole fraction of species $k$, and $D_{i k}$ is the binary diffusivity between species $i$ and $k$. The rate expression for the production or consumption of species $i$ is defined as

$$
R_{i}=M_{i} R_{r}
$$

\section{$\underline{3.2}$ Boundary conditions and solution methodology}

The above governing equations require boundary conditions. Since the brass manifolds are not explicitly modeled, the heat-sink effect of the brass manifolds was accounted for using an isothermal boundary condition, which was found to have a negligible impact on the numerical temperature profile because the defects studied are located at the center of the sample. Between solid and gas phases, the model assumes local thermal equilibrium. 
For the energy equation, a thermal boundary condition at the inlet manifold/GDL interface is specified by the gas-mixture temperature,

$$
T=T_{\text {in }} \text { for } \partial \Omega \in z=0
$$

where $\partial \Omega$ represents the boundary of the computational domain. At the outlet manifold/CL interface, a convective cooling boundary condition is assigned,

$$
n \cdot\left(-k_{\mathrm{CL}} \nabla T\right)=h_{\mathrm{conv}}\left(T-T_{\text {room }}\right) \text { for } \partial \Omega \in z=t_{L}
$$

where $t_{L}$ is the combined thickness of GDL, MPL, and CL layer and $h_{\text {conv }}$ is the equivalent convection heat-transfer coefficient that is estimated using an expression similar to Handley and Heggs expression [21]:

$$
h_{\mathrm{conv}}=a_{f}\left[\frac{0.255 k_{f}}{W \varepsilon_{\mathrm{CL}}} \operatorname{Pr} \frac{1}{3} \operatorname{Re}_{D} \frac{2}{3}\right]
$$

where $\operatorname{Pr}$ and $\operatorname{Re}_{D}$ are the Prandlt number of the gas-mixture and Reynolds number based on manifold inlet diameter, respectively, and $a_{f}$ is a fitting parameter which is fit once and then not varied among the different simulation cases. The Prandlt number of the gas-mixture is estimated using the mixture composition, while the Reynolds number is estimated using the following expression.

$$
\operatorname{Re}_{D}=\frac{q_{m} D}{A v}
$$

where $q_{m}$ is the gas flowrate, $D$ is the inlet-tube diameter, $A$ is the area, and $v$ is the kinematic viscosity. 
For the mass conservation equation, inlet mass-flux is defined based on the gas flowrate, while a pressure boundary condition is applied the outlet manifold/CL interface as

$$
p=p_{\text {room }} \text { for } \partial \Omega \in z=t_{L}
$$

For the species transport equation, inlet mass-fractions are defined based on the gas-mixture composition, while a Neumann boundary condition is applied at the outlet manifold/CL interface

$$
\nabla \omega_{i}=0 \text { for } \partial \Omega \in z=t_{L}
$$

For all other boundaries an insulation or a symmetry boundary condition is applied.

The governing equations were solved using commercial finite-element software COMSOL Multiphysics $^{\circledR}$. The 3D computational domain was discretized into a tetrahedral mesh and second-order Lagrangian elements were used with the Direct solver. The solutions were considered converged when the tolerance value was below $10^{-5}$ and were mesh independent (at least $30 \times 35 \times 35$ elements).

\section{RESULTS AND DISCUSSION}

\subsection{Pristine samples and model validation}

To understand the viability of the technique, pristine GDEs, i.e., GDEs with nominally uniform Pt loading were fabricated and tested in the setup shown in Figure 1. Figure 3 shows IR thermographs of a pristine sample at steady state over a range of flowrates. It is apparent that the heat signature from the $\mathrm{CL}$ is readily detectable, owing to the large heat of reaction of hydrogen. It should be noted that IR thermography is essentially a surface technique, although the thinness of the CL ensures that the temperature is uniform through the thickness of the layer. The heat of reaction is removed through the top and bottom CL surfaces, by convection with the gas stream, 
and by conduction to the brass manifolds. This resulting thermal balance results in Figure 3 . The in-plane temperature gradient observed in the thermographs is due mainly to the presence of the large thermal mass of the brass manifold that essentially induces an isothermal boundary, and may also be due to some channeling of the flow in the middle of the domain. Figure 3 also shows the increase in heat signature from 31 to $36^{\circ} \mathrm{C}$ as the gas mixture flowrate is increased three-fold. The increased flowrate corresponds to an increased flux and thus rate of reaction of the hydrogen.

To understand the impact of flowrate in more detail, Figure 4 shows the maximum and average temperature rise for the pristine sample as a function of flowrate. The maximum temperature represents the highest temperature measured, while the average temperature represents the mean temperature within a collection window of about $75 \%$ of the total sample area around the center of the sample as shown in Figure 3(a). The size of the collection window was kept smaller than the sample area to minimize the edge effects observed in Figure 3. The two temperatures track consistently, which is expected since the data originate from the same set of experiments. The shape of the curves in Figure 4 is the result of two competing processes. Below $1500 \mathrm{sccm}$ the temperature increases with increasing flowrates due to an increase in hydrogen flux and thus a higher reaction rate. However, as the flowrate becomes larger than $1500 \mathrm{sccm}$ a plateau is reached. This was attributed to complete utilization of all active Pt catalyst sites in the CL. In other words, at gas flows above $1500 \mathrm{sccm}$ hydrogen is flowing through the CL without reacting. At flowrates above $2500 \mathrm{sccm}$ the temperature decreases due to what we believe to be increased convective cooling of the GDE. 
To explore the energy balance and parameter space in more detail, a mathematical model was formulated as described above. The model was validated by comparison of the temperature rise of different pristine GDE samples as shown in Figure 5 for various nominal Pt loadings and hydrogen concentrations at a flowrate of $1500 \mathrm{sccm}$. As shown, the model predictions demonstrate good agreement with the experimental data for various Pt loadings with a few percent error. The data in Figure 5(a) indicate increased extent of reaction of hydrogen with increasing Pt loading and confirm that at these specific experimental conditions, and over the range of loadings studied, not all hydrogen is reacting and contributing to the heat signature of the GDE.

Figure 5(b) shows the impact of hydrogen concentration in the reactive gas mixture on the temperature response. For this effect, the value comparison between model and experiment are in even closer agreement than the comparison in Figure5(a), which also highlights the fact that the model does not require re-calibration for the different concentrations. It is also apparent that the temperature response is highly sensitive to the hydrogen concentration, where going towards $2 \%$ provides over a six-fold increase in the temperature rise; it should be noted that $2 \%$ is still only half of the flammability limit of hydrogen in air.

\subsection{Detection of defects}

In this section we examine the feasibility of the introduced IR-RFT method to detect defects that were intentionally introduced into the CL. Square defects of different sizes and degrees were tested and square and rectangular defects simulated with different flowrates, nominal Pt loadings, and hydrogen concentrations. 
Figure 6 (a), (b) and (c) show IR thermographs and corresponding temperature profiles of $5 \mathrm{~cm} \times$ $5 \mathrm{~cm}$ GDE samples with square defects at the center of the sample. Data is shown for a gas flowrate of $1500 \mathrm{sccm}$ at 10 and $20 \mathrm{~s}$ as thermographs in the left and center, respectively, and as temperature profiles along the dashed line in the right. The nominal Pt loading of the pristine area was $0.2 \mathrm{mg} \mathrm{cm}^{-2}$. Figure 6(a) shows results for a $2 \mathrm{~cm}^{2}$ square $100 \%$ loading reduction defect, i.e. a $2 \mathrm{~cm}^{2}$ area without any Pt loading. The defect was indicated after $10 \mathrm{~s}$ by a temperature reduction of over $4^{\circ} \mathrm{C}$, which is apparent in the thermographic image on the left as well as the temperature profile on the right.

In Figure 6(b), results are shown for a $0.25 \mathrm{~cm}^{2}$ defect with a $100 \%$ loading reduction. The temperature variation at the defect location is about $1^{\circ} \mathrm{C}$. Thus, the defect is detectable but it could be possibly enhanced by, for example, increasing the gas flowrate as indicated by Figure 4 or by increasing the hydrogen concentration as indicated by Figure 5(b)). A smaller defect, in this case a $50 \%$ loading reduction of the same size, becomes more challenging to detect as shown in Figure 6(c). Although after $20 \mathrm{~s}$ the defect signature is visible in the temperature profile, the temperature differential is very small.

To enhance the signal, as mentioned, a higher flowrate of inlet gas could potentially be used. Figure 7(a) and (b) show the maximum, minimum, and differential temperature-time profiles of a $5 \mathrm{~cm} \times 5 \mathrm{~cm}$ defect GDE sample with a $1 \mathrm{~cm}^{2} 50 \%$ defect at the center for gas flows of 1500 and $5000 \mathrm{sccm}$, respectively. The temperature rise for $5000 \mathrm{sccm}$ is faster than for the $1500 \mathrm{sccm}$ case, thus showing that one can obtain response times on the order of a few seconds. However, 
the temperature increase is larger for the $1500 \mathrm{sccm}$ case because of the increased convective cooling at $5000 \mathrm{sccm}$.

As seen in Figure 7, one must be cognizant of choice of design criteria since just using the maximum temperature is not necessarily the best metric since variations in defects and loadings could give profiles that fluctuate and thus a threshold criterion may become ill-defined. Similarly, the temperature difference, if used, must be carefully defined with respect to a reference or average temperature.

To understand the impact of flowrate in more detail, simulations at different flowrates were conducted. Figure 8 shows the steady-state temperature profiles, the extent of reaction for the $\mathrm{H}_{2} / \mathrm{O}_{2}$ mixture, and the pressure drop through the GDE. The steady-state temperature profiles are shown from the middle of one edge to the center of a $5 \mathrm{~cm} \times 5 \mathrm{~cm}$ electrode with a $1 \mathrm{~cm}^{2}$ square defect at the center for various gas-mixture flowrates and for Pt loading of (a) $0.2 \mathrm{mg}-\mathrm{Pt}$ $\mathrm{cm}^{-2}$ and (b) $0.4 \mathrm{mg}-\mathrm{Pt} \mathrm{cm}{ }^{-2}$. The extents of reaction are shown as the percentage hydrogen mass fractions at the exit of the GDE for various flowrates and for Pt loading of (c) $0.2 \mathrm{mg}-\mathrm{Pt} \mathrm{cm} \mathrm{cm}^{-2}$ and (d) $0.4 \mathrm{mg}-\mathrm{Pt} \mathrm{cm}{ }^{-2}$. The pressure drop (difference between the local pressure and ambient pressure) data in Figure 8(e) are presented along the thickness of the sample for two flowrates under the defect area and the pristine area for Pt loading of $0.2 \mathrm{mg}-\mathrm{Pt} \mathrm{cm}^{-2}$. Similar to the experimental data, the modeling results show that the temperature in the pristine area is always higher than the temperature in the defect area. Also, a higher loading always generates a higher temperature due to more complete combustion of the hydrogen. As shown in Figures 8(c) and 8(d), the exit mass-fraction percentage of hydrogen is significantly higher for lower loadings. In fact, doubling of the loading doubled the differential temperature. Figure 8 reveals that higher 
gas flowrates result in lower temperatures in both the pristine and defect areas. However, the differential temperatures between the pristine and defect areas seem almost independent of the gas flowrate, which is a key finding in terms of optimizing detection and response time. In other words, high flow rates enable faster response times because reactants reach the catalyst layer faster (see Figure 7), while still maintaining a detectable differential temperature. The pressuredrop data reveal that the entire pressure drop is happening between the MPL and CL with a negligible pressure drop in the GDL. The simulation data also reveal that heat convection and conduction are not dominant in the experimental set-up as the temperature is within $1{ }^{\circ} \mathrm{C}$ of the predicted adiabatic temperature rise (i.e., assuming no heat transfer out of the catalyst layer). For instance, the adiabatic temperature rise in the pristine are for $0.2 \mathrm{mg}-\mathrm{Pt} \mathrm{cm}^{-2}$ loading and 1000 sccm is about $6.5^{\circ} \mathrm{C}$, whereas the actual temperature rise is $5.7^{\circ} \mathrm{C}$. However, the variation between the adiabatic and the actual temperature rise is slightly higher at higher flowrates due to higher convective heat removal.

Using the model, one can predict the detection limit of the technique relative to different degrees of defect, defined as the percent of loading reduction, where $0 \%$ loading reduction indicates a pristine electrode and 100\% loading reduction indicates a bare spot. Figure 9 shows the differential temperature between the pristine and defect areas as a function of defect degree. Interestingly, the data is almost linear with defect degree. The lower flowrate provides a slightly higher temperature rise than the higher flowrate, which is due to the convective cooling effect at the higher flowrate (see Figure 4). However, when using the detection limit we defined in our previous work for IR-DC [17], i.e. $\Delta \mathrm{T}=1^{\circ} \mathrm{C}$, the effect of flowrate is minor. The effect of flowrate, and thus convective cooling, becomes more prominent as reduction of loading in the 
defect area increases. Figure 9 also reveals that, for this defect and with a $1{ }^{\circ} \mathrm{C}$ detection limit, the limitation on detecting the degree of the defect is when the loading reduction in the defect area is less than $22 \%$ of the nominal loading.

The data shown in Figure 5 predicted that the thermal response of a pristine GDE can potentially be increased by increasing the hydrogen concentration. Figure 10 shows a similar prediction for the differential temperature caused by a defect. The simulations indicate that by increasing the hydrogen concentration in the inlet gas stream, smaller defects may be able to be detected. Clearly, higher hydrogen concentrations raise the reaction rate and generate a greater differential temperature. Therefore, a defect that is not detectable with $0.4 \%$ hydrogen (see Figure 9) may be able to be detected by increasing hydrogen concentration in the inlet gas-stream (of course for safety reasons one wants to remain below the flammability limit of $4 \% \mathrm{H}_{2}$ ). In fact, increasing the hydrogen concentration is preferable to increasing the hydrogen gas flow, because the latter increases the amount of counterproductive convective cooling. Increasing the hydrogen concentration five-fold, from 0.4 to $2 \%$, provides an almost seven-fold increase in temperature difference for this defect at a flowrate of $1000 \mathrm{sccm}$. Thus, when using $2 \% \mathrm{H}_{2}$ and $1 \% \mathrm{O}_{2}$ in $\mathrm{N}_{2}$, the sensitivity for detecting defects will be enhanced and, assuming a detection criteria of $1^{\circ} \mathrm{C}$ variation, smaller defects may become detectable (e.g., simulations show down to $0.0625 \mathrm{~cm}^{2}$ for bare spots).

To understand the impact of defect shape (such as non-square defect or micro-crack), simulation results are presented in Figure 11 that study the effect of the defect aspect ratio $(A R)$, which is defined as the height $(H)$ to width $(W)$ ratio of the defect. Figure 11(a) shows the temperature profiles across the electrode along the white dashed line shown in the simulated thermographic 
image shown in Figure 11(b) and (c) show the temperature differential between defect and nondefect area for a fixed defect height of $5 \mathrm{~mm}$ and different defect widths ranging from $5 \mathrm{~mm}$ to $200 \mu \mathrm{m}$. As observed in the temperature profiles, the maximum temperature in the pristine area remains identical for all the aspect ratios; however, the temperature in the defect region decreases as the aspect ratio increases. The results of Figure 11(c) show that for narrower defect geometries such as, for example, a micro-crack $(200 \mu \mathrm{m} \times 5 \mathrm{~mm}$ crack, $A R=25)$, the temperature rise between the defect and non-defect area decreases. It is further predicted that for such a micro-crack, the temperature differential is larger than $3^{\circ} \mathrm{C}$ when using $2 \% \mathrm{H}_{2}$ containing gas. Therefore, the current technique may be capable of detecting micro-cracks when using higher hydrogen concentrations. In theory, the IR-detection sensitivity can be as good as a few micrometers and with use of the higher concentrations and optimal flowrate, the micro-cracks and micro-defects that are expected to be troublesome in the fuel cells may possibly be detected.

\section{IMPLEMENTATION ON WEB-LINE}

\subsection{Flow arrangement}

The experimental hardware introduced in this work is the first experimental development step towards an IR-RFT based diagnostic system that is envisioned to operate on an industrial processing line. One common method to apply gases in such a web environment is through the use of a gas knife, which transports the gas through either a slit or an array of holes onto the moving web to create an impinging flow. Thus, instead of a uniform flux as shown in Figure 1 throughout the domain of interest, there would be a more complicated flow distribution onto and around the GDE. While an analysis of this situation is beyond the scope of this paper, it is worthwhile to examine if such a slit or line flow through the GDE is feasible for the detection of 
defects. The setup in Figure 1 and the model domain in Figure 2 were modified as shown in Figure 12(a) such that flow only occurred through a slit. The slit was created by adding a PTFE sheet that contained a $3 \mathrm{~mm}$ wide rectangular cut-out to the inlet-side of the GDE. From the thermographic image shown in Figure 12(b), which shows the results of a $2 \mathrm{~cm}^{2} 100 \%$ reduction defect, it is apparent that the bare spot is still detectable. Thus, the analyses, results, and discussion presented above for a flow-through technique leads us to believe that a suitably modified technique is promising for implementation on a web-line. The impact of impinging flow and flow penetration into the CL, rather than through the GDL and MPL, will be critical to a web-line implementation and is currently being investigated.

\subsection{Non-destructiveness}

Temperature rises have been observed and predicted that ranged up to $35^{\circ} \mathrm{C}$ for $0.4 \% \mathrm{H}_{2}$ and to $70^{\circ} \mathrm{C}$ for $2 \% \mathrm{H}_{2}$, respectively. While these temperature increases specifically for the latter concentration may appear large, they are still below typical operating temperatures of PEMFCs. For example, the most susceptible component may be the ionomer, but the $\alpha$-transition temperature of Nafion is over $100^{\circ} \mathrm{C}$ [22] and thus morphological changes are not expected even for the case with $2 \%$ or slightly higher hydrogen concentrations. In addition, both the experimental and numerical results shown are for non-moving materials that are continuously excited, i.e. for up to $20 \mathrm{~s}$ in the experimental data and steady state solutions for the numerical models. Application of this technique in a web-line environment involves diagnosing moving GDE substrates. Thus excitation of any point of the GDE is only applied for a few seconds and the temperature rise is expected to be lower than reported here. The final temperature rise on a web-line will be a function of web speed, gas flow, gas composition, and potentially other 
parameters. Thus, the technique is expected to be non-destructive to the catalyst and the GDE in general.

\section{CONCLUSIONS}

Quality-control diagnostics of fuel-cell materials and components are required for high-volume production of fuel cells. The first development stage of a non-destructive, rapid technique to measure Pt-loading variations in mass-produced gas-diffusion electrodes was introduced. This development stage of the diagnostic technique involves flowing a dilute hydrogen/oxygen gas mixture through the gas-diffusion electrode, and then measuring the subsequent temperature response due to the reaction of the hydrogen with oxygen on $\mathrm{Pt}$ using infrared thermography. Both experiments and modeling demonstrate that this technique allows one to resolve spatially the variations in the catalyst-layer loadings by thermographic imaging, where the temperature response is a function of the Pt loading.

The technique was successfully employed to detect a variety of catalyst layer defects that were intentionally introduced into the GDE. The signal strength and speed for defect recognition was found to be dependent on the applied operating parameters. Increasing the inlet gas flowrate reduces the time required for detecting defects, however, increased flowrates were also observed to result in convective cooling and a decrease in the maximum temperature. The hydrogen concentration of the gas mixture was identified as a key parameter for using the technique. Modeling work indicated that for the given operating conditions the temperature response could be enhanced by $10^{\circ} \mathrm{C}$ or more when switching from a hydrogen concentration of $0.4 \%$ to concentrations of $2 \%$ or higher. 
The results demonstrated on the first development stage of this technique show great promise for further development to an in-line quality-control diagnostic for fuel-cell gas-diffusion electrodes. The technique is cost effective, rapid, allows for $100 \%$ areal inspection, and utilizes only nonhazardous gas, i.e., a $\mathrm{H}_{2} / \mathrm{O}_{2}$ gas composition that is well below the flammability limit. Future work will focus on the second development stage of this technique: the transition from a static sample chamber with non-moving sample materials shown in this work to moving sample materials in an open exposed environment.

\section{ACKNOWLEDGEMENTS}

The authors acknowledge funding for this work provided by the Fuel Cell Technologies Office,

of the U. S. Department of Energy, Energy Efficiency and Renewable Energy under contract numbers DE-AC36-08-GO28308 (NREL) and DE-AC02-05CH11231 (LBNL). 


\section{REFERENCES}

[1] M.F. Mathias, R. Makharia, H.A. Gasteiger, Jason J. Conley, T.J. Fuller, C.J. Gittleman, S.S. Kocha, Daniel P. Miller, C.K. Mittelsteadt, T. Xie, S.G. Yan, P.T. Yu, The Electrochemical Society Interface, 14 (2005) 24-35.

[2] M.K. Debe, Nature, 486 (2012) 43-51.

[3] A.Z. Weber, J. Newman, J. Electrochem. Soc., 153 (2006) A2205-A2214.

[4] S. Kundu, M. Fowler, L. Simon, S. Grot, J. Power Sources, 157 (2006) 650-656.

[5] A.Z. Weber, J. Newman, J. Electrochem. Soc., 154 (2007) B405-B412.

[6] P.K. Das, X. Li, Z.S. Liu, J. Electroanal. Chem., 604 (2007) 72-90.

[7] M. Pestrak, Y. Li, S.W. Case, D.A. Dillard, M.W. Ellis, Y.H. Lai, C.S. Gittleman, J. Fuel Cell Sci. Tech., 7 (2010) 041009.

[8] P.K. Das, X. Li, Z. Xie, Z.S. Liu, Int. J. Energ. Res., 35 (2011) 1325-1339.

[9] P.K. Das, X. Li, Z.S. Liu, Int. J. Hydrogen. Energ., 35 (2010) 2403-2416.

[10] R. Borup, J. Meyers, B. Pivovar, Y.S. Kim, R. Mukundan, N. Garland, D. Myers, M.

Wilson, F. Garzon, D. Wood, P. Zelenay, K. More, K. Stroh, T. Zawodzinski, J. Boncella, J.E. McGrath, M. Inaba, K. Miyatake, M. Hori, K. Ota, Z. Ogumi, S. Miyata, A. Nishikata, Z. Siroma, Y. Uchimoto, K. Yasuda, K.I. Kimijima, N. Iwashita, Chemical Reviews, 107 (2007) 3904-3951.

[11] Y. Li, D.A. Dillard, S.W. Case, M.W. Ellis, Y.-H. Lai, C.S. Gittleman, D.P. Miller, J. Power Sources, 194 (2009) 873-879.

[12] C. Wyon, D. Delille, J.P. Gonchond, F. Heider, L. Kwakman, S. Marthon, I. Mazor, A. Michallet, D. Muyard, L. Perino-Gallice, J.C. Royer, A. Tokar, Thin Solid Films, 450 (2004) 8489.

[13] C. Wyon, J.P. Gonchond, D. Delille, A. Michallet, J.C. Royer, L. Kwakman, S. Marthon, Appl Surf Sci, 253 (2006) 21-27.

[14] M.A. Sapia, J.G. Clark, in: U.S. Patent (Ed.), Amdata, Inc., 1992.

[15] G.J. Lamont, D.P. Wilkinson, in: U.S. Patent (Ed.), Ballard Power Systems Inc. , 1998.

[16] M. Boehmisch, C. Haas, in: U.S. Patent (Ed.), DaimlerChrysler AG, 2006.

[17] N.V. Aieta, P.K. Das, A. Perdue, G. Bender, A.M. Herring, A.Z. Weber, M.J. Ulsh, J. Power Sources, 211 (2012) 4-11.

[18] T. Berning, D.M. Lu, N. Djilali, J. Power Sources, 106 (2002) 284-294.

[19] P.K. Das, X. Li, Z.S. Liu, Appl. Energ., 87 (2010) 2785-2796.

[20] T. Mitani, F.A. Williams, Combustion and Flame, 39 (1980) 169-190.

[21] D. Handly, P.J. Heggs, Trans. Inst. Chem. Eng., 46 (1968) T251-T264.

[22] K.A. Mauritz, R.B. Moore, Chemical Reviews, 104 (2004) 4535-4585. 


\section{Figure Captions}

Figure 1. (a) Experimental setup of IR-RFT method and (b) GDE sample with a square defect (bare spot) in the center marked by dashed rectangle.

Figure 2. (a) Schematic of the RFT experimental setup with computational domain marked by dashed line. (b) Full computational domain.

Figure 3. Heat signatures at steady state over a range of flowrates. The GDE used is pristine with a loading of $0.1 \mathrm{mg}-\mathrm{Pt} \mathrm{cm} \mathrm{cm}^{-2}$ and $0.4 \% \mathrm{H}_{2}$ and $0.2 \% \mathrm{O}_{2}$ in $\mathrm{N}_{2}$ gas-mixture. The dashed rectangle in part (a) is the data collection window, which is about $75 \%$ of the total sample area.

Figure 4. Measured temperature rise as a function of gas flowrate for pristine GDE with Pt loading of $0.1 \mathrm{mg}-\mathrm{Pt} \mathrm{cm} \mathrm{cm}^{-2}$ and $0.4 \% \mathrm{H}_{2}$ and $0.2 \% \mathrm{O}_{2}$ in $\mathrm{N}_{2}$ gas-mixture. Error bars show $90 \%$ confidence intervals for seven total runs.

Figure 5. Comparisons between experimental measurements and model predictions for $5 \mathrm{~cm} \times 5$ $\mathrm{cm}$ pristine samples at a gas flowrate of $1500 \mathrm{sccm}$ : Temperature rise as a function of (a) nominal loading for $0.4 \% \mathrm{H}_{2}$ and $0.2 \% \mathrm{O}_{2}$ in $\mathrm{N}_{2}$, and (b) hydrogen concentration for a nominal Pt loading of $0.4 \mathrm{mg}-\mathrm{Pt} \mathrm{cm}^{-2}$.

Figure 6. IR thermographs at 10 and $20 \mathrm{~s}$, and corresponding line temperature profiles of $5 \mathrm{~cm} \times$ $5 \mathrm{~cm}$ defect samples with $0.2 \mathrm{mg}-\mathrm{Pt} \mathrm{cm}{ }^{-2}$ nominal loading at $1500 \mathrm{sccm}$ of $0.4 \% \mathrm{H}_{2}$ and $0.2 \% \mathrm{O}_{2}$ in $\mathrm{N}_{2}$ : (a) $2 \mathrm{~cm}^{2}$ defect of $100 \%$ loading reduction (i.e. a bare spot), (b) $0.25 \mathrm{~cm}^{2}$ defect of $100 \%$ loading reduction, and (c) $0.25 \mathrm{~cm}^{2}$ defect of $50 \%$ loading reduction.

Figure 7. Temperature profiles of a $5 \mathrm{~cm} \times 5 \mathrm{~cm}$ GDE sample with $0.2 \mathrm{mg}-\mathrm{Pt} \mathrm{cm}^{-2}$ nominal loading and $1 \mathrm{~cm}^{2} 50 \%$ defect using $0.4 \% \mathrm{H}_{2}$ and $0.2 \% \mathrm{O}_{2}$ in $\mathrm{N}_{2}$ at (a) 1500 and (b) $5000 \mathrm{sccm}$, respectively. 
Figure 8. Simulated (a,b) temperature profiles, (c,d) extents of reaction, and (e) pressure drop through a $5 \mathrm{~cm} \times 5 \mathrm{~cm}$ GDE with $1 \mathrm{~cm}^{2} 50 \%$ defect with various gas-mixture flowrates using $0.4 \% \mathrm{H}_{2}$ and $0.2 \% \mathrm{O}_{2}$ in $\mathrm{N}_{2}$. The temperature profiles are from CL edge to defect center for loadings of (a) $0.2 \mathrm{mg}-\mathrm{Pt} \mathrm{cm} \mathrm{cm}^{-2}$ and (b) $0.4 \mathrm{mg}-\mathrm{Pt} \mathrm{cm}{ }^{-2}$, the extents of reaction are presented as the exit mass-fraction percentage of hydrogen for (c) $0.2 \mathrm{mg}-\mathrm{Pt} \mathrm{cm}{ }^{-2}$ and (d) $0.4 \mathrm{mg}-\mathrm{Pt} \mathrm{cm}{ }^{-2}$, and the pressure-drop data are for $0.2 \mathrm{mg}-\mathrm{Pt} \mathrm{cm}^{-2}$.

Figure 9. Temperature rise between the defect and non-defect area as a function of defect loading for a $1 \mathrm{~cm}^{2}$ defect at two different flowrates for a $5 \mathrm{~cm} \times 5 \mathrm{~cm}$ GDE sample with a $1 \mathrm{~cm}^{2}$ defect.

Figure 10. Temperature differential between the defect and non-defect (pristine) area as a function of hydrogen concentration for a $5 \mathrm{~cm} \times 5 \mathrm{~cm}$ GDE sample with a $1 \mathrm{~cm}^{2} 50 \%$ loading reduction defect at two different flowrates.

Figure 11. Modeling predictions for a gas mixture of $2 \% \mathrm{H}_{2}$ and $1 \% \mathrm{O}_{2}$ in $\mathrm{N}_{2}$, a variety of geometric aspect rations and flows. (a) Effect of geometric aspect ratio of the defect on the temperature profiles across the electrode along the white dashed line for a 50\% loading and 0.5 $\mathrm{cm}$ wide defect. (b) Modeling results of thermographic image with geometric aspect ratio of 1. (c) Temperature differential between defect and non-defect area as a function of aspect ratio at two different flowrates.

Figure 12. (a) Experimental configuration for line flow experiment using a slotted gasket. (b) Thermographic image of a $2 \mathrm{~cm}^{2}, 100 \%$ reduction, $0.2 \mathrm{mg}-\mathrm{Pt} \mathrm{cm} \mathrm{cm}^{-2}$ nominal loading sample at a flowrate of $3000 \mathrm{sccm}$ and hydrogen concentration of $0.4 \%$. 


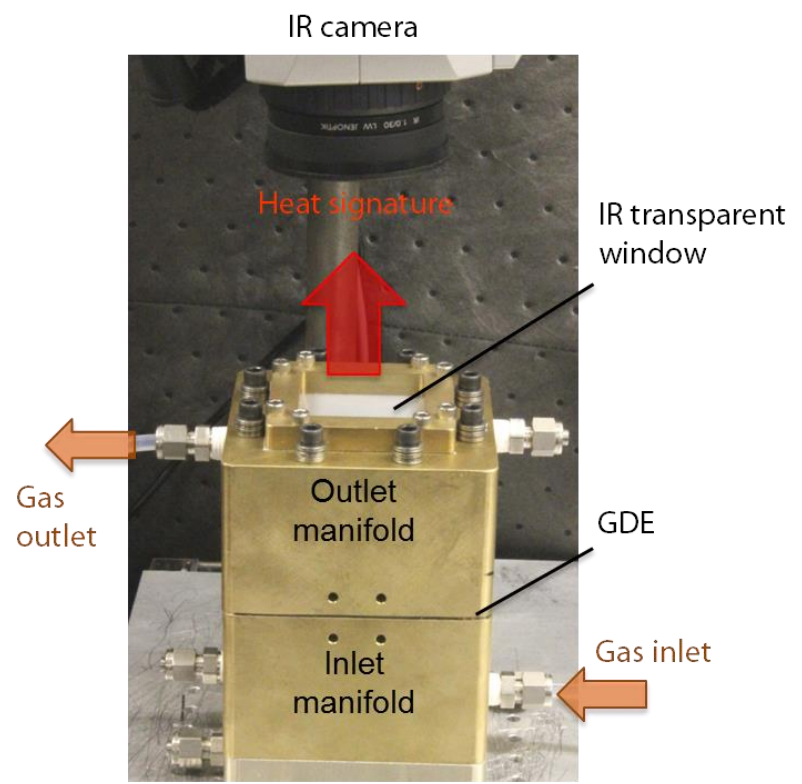

(a)

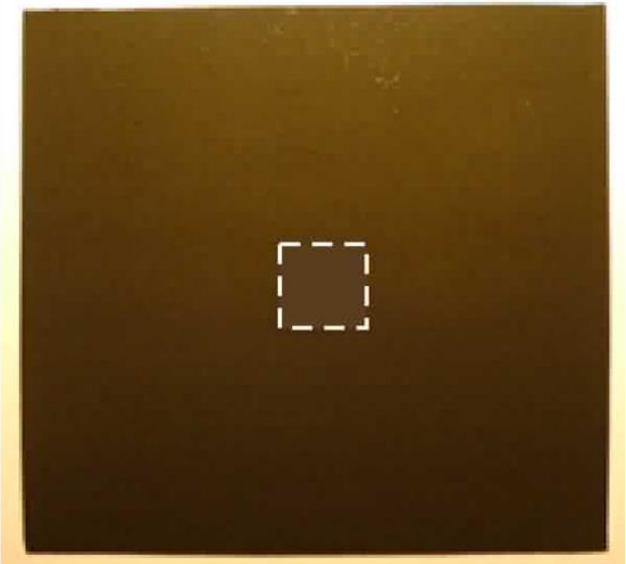

(b)

Figure 1. (a) Experimental setup of IR-RFT method and (b) GDE sample with a square defect (bare spot) in the center marked by dashed rectangle. 


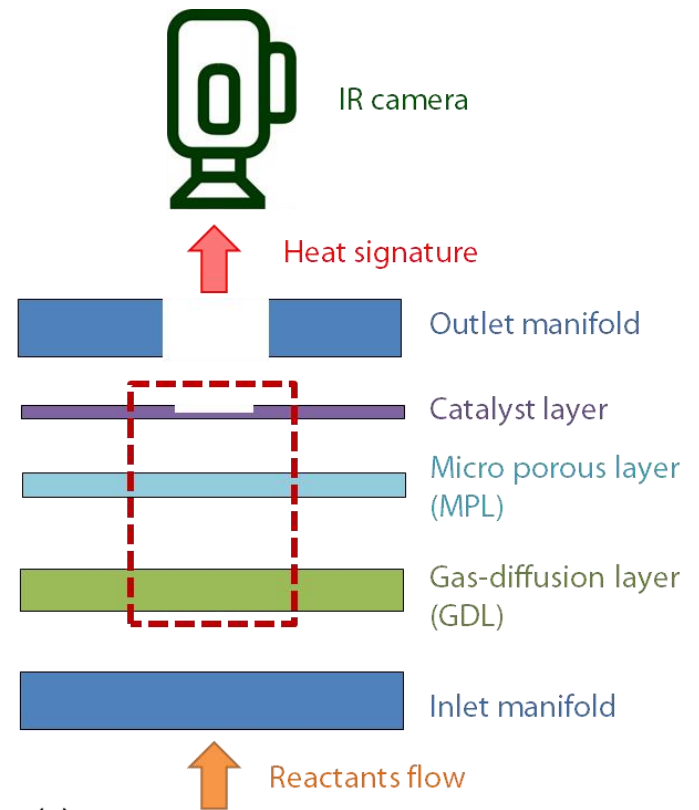

(a)

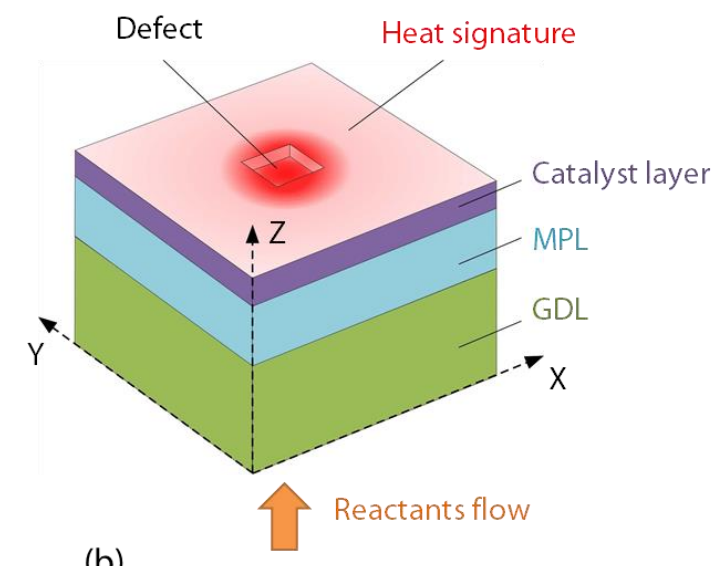

(b)

Figure 2. (a) Schematic of the RFT experimental setup with computational domain marked by dashed line. (b) Full computational domain. 


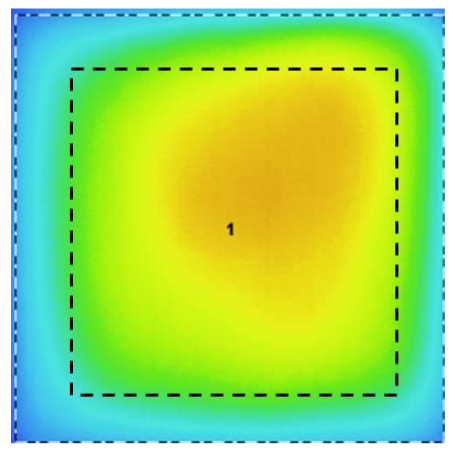

(a) $500 \mathrm{sccm}$

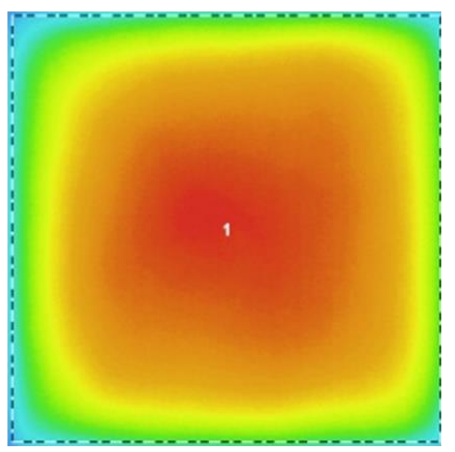

(b) $1000 \mathrm{sccm}$

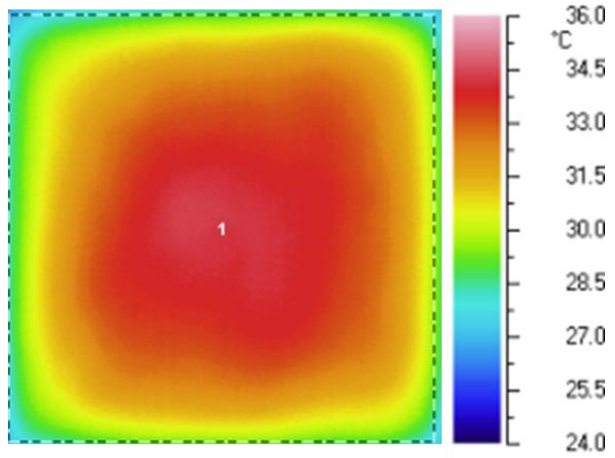

(c) $1500 \mathrm{sccm}$

Figure 3. Heat signatures at steady state over a range of flowrates. The GDE used is pristine with a loading of $0.1 \mathrm{mg}-\mathrm{Pt} \mathrm{cm} \mathrm{cm}^{-2}$ and $0.4 \% \mathrm{H}_{2}$ and $0.2 \% \mathrm{O}_{2}$ in $\mathrm{N}_{2}$ gas-mixture. The dashed rectangle in part (a) is the data collection window, which is about $75 \%$ of the total sample area. 


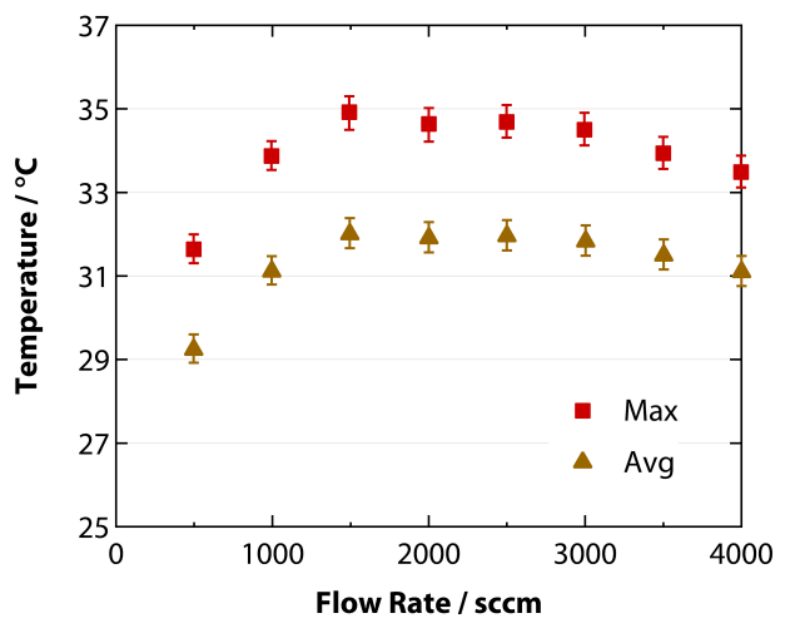

Figure 4. Measured temperature rise as a function of gas flowrate for pristine GDE with $\mathrm{Pt}$ loading of $0.1 \mathrm{mg}-\mathrm{Pt} \mathrm{cm} \mathrm{cm}^{-2}$ and $0.4 \% \mathrm{H}_{2}$ and $0.2 \% \mathrm{O}_{2}$ in $\mathrm{N}_{2}$ gas-mixture. Error bars show $90 \%$ confidence intervals for seven total runs. 

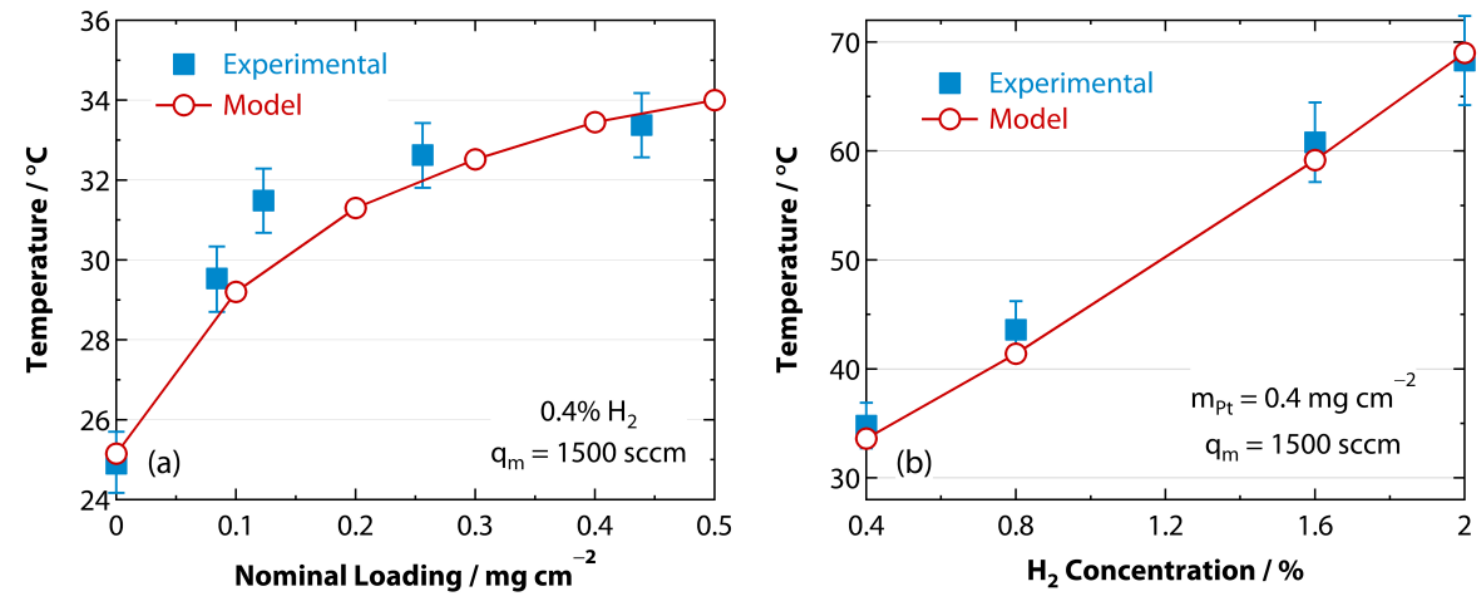

Figure 5. Comparisons between experimental measurements and model predictions for $5 \mathrm{~cm} \times 5$ $\mathrm{cm}$ pristine samples at a gas flowrate of $1500 \mathrm{sccm}$ : Temperature rise as a function of (a) nominal loading for $0.4 \% \mathrm{H}_{2}$ and $0.2 \% \mathrm{O}_{2}$ in $\mathrm{N}_{2}$, and (b) hydrogen concentration for a nominal Pt loading of $0.4 \mathrm{mg}-\mathrm{Pt} \mathrm{\textrm {cm } ^ { - 2 }}$. 

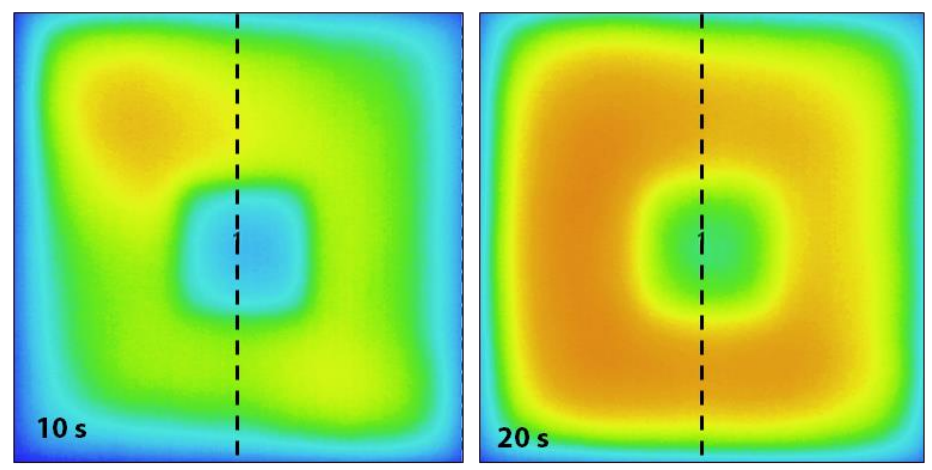

(a) $2 \mathrm{~cm}^{2}$ bare spot
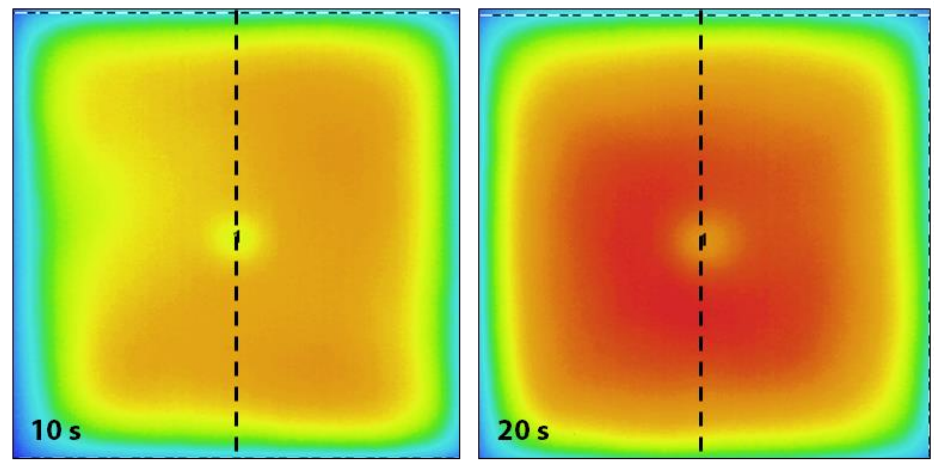

(b) $0.25 \mathrm{~cm}^{2}$ bare spot
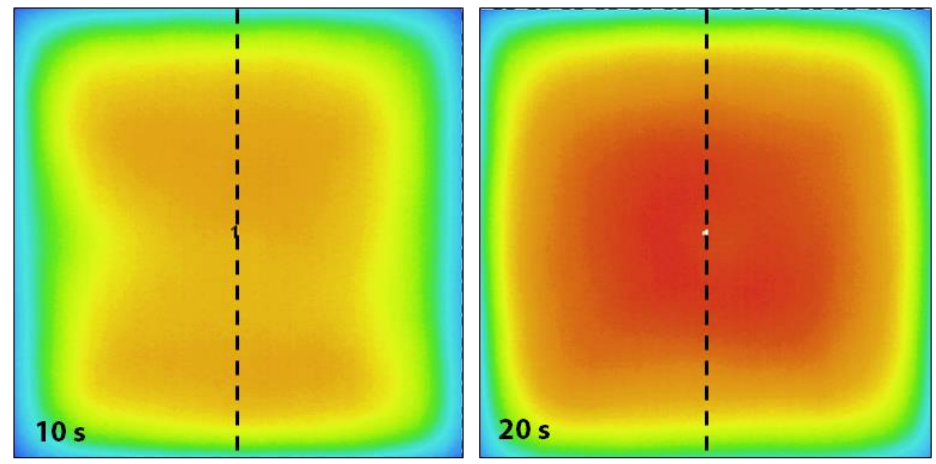

(c) $0.25 \mathrm{~cm}^{2} 50 \%$ defect
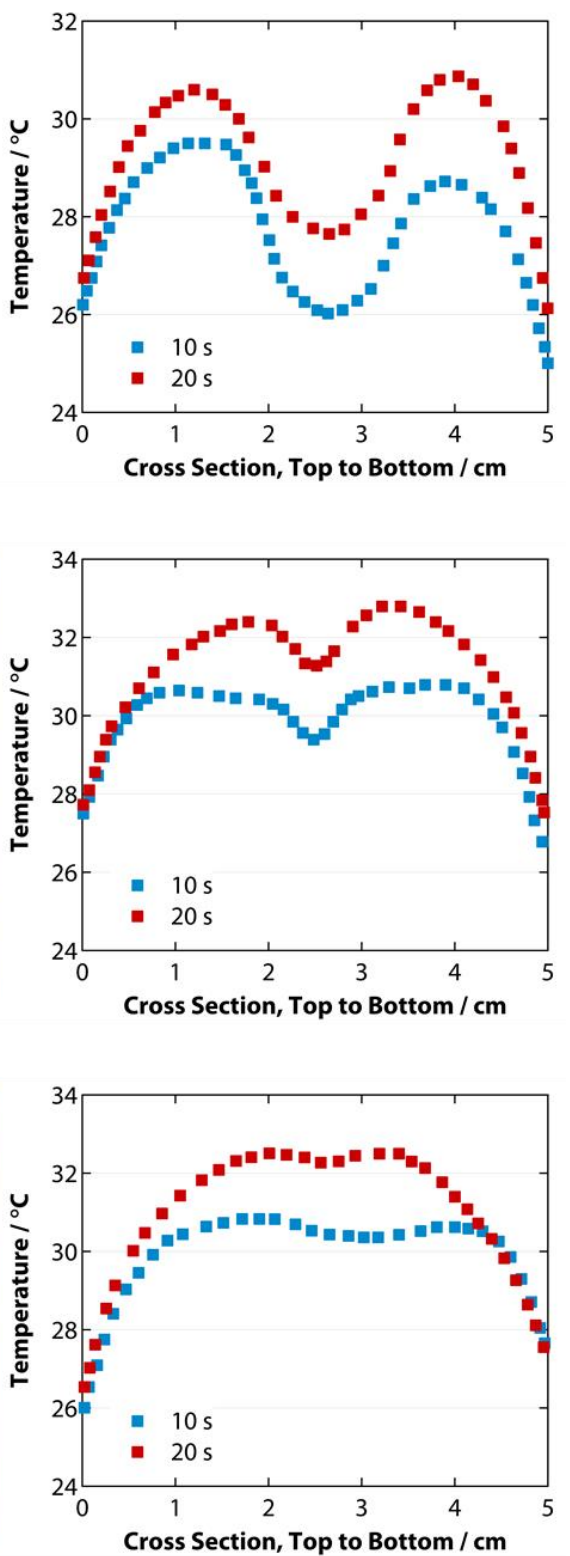

Cross Section, Top to Bottom / cm

Figure 6. IR thermographs at 10 and $20 \mathrm{~s}$, and corresponding line temperature profiles of $5 \mathrm{~cm} \times$ $5 \mathrm{~cm}$ defect samples with $0.2 \mathrm{mg}-\mathrm{Pt} \mathrm{cm} \mathrm{cm}^{-2}$ nominal loading at $1500 \mathrm{sccm}$ of $0.4 \% \mathrm{H}_{2}$ and $0.2 \% \mathrm{O}_{2}$ in $\mathrm{N}_{2}$ : (a) $2 \mathrm{~cm}^{2}$ defect of $100 \%$ loading reduction (i.e. a bare spot), (b) $0.25 \mathrm{~cm}^{2}$ defect of $100 \%$ loading reduction, and (c) $0.25 \mathrm{~cm}^{2}$ defect of $50 \%$ loading reduction. 

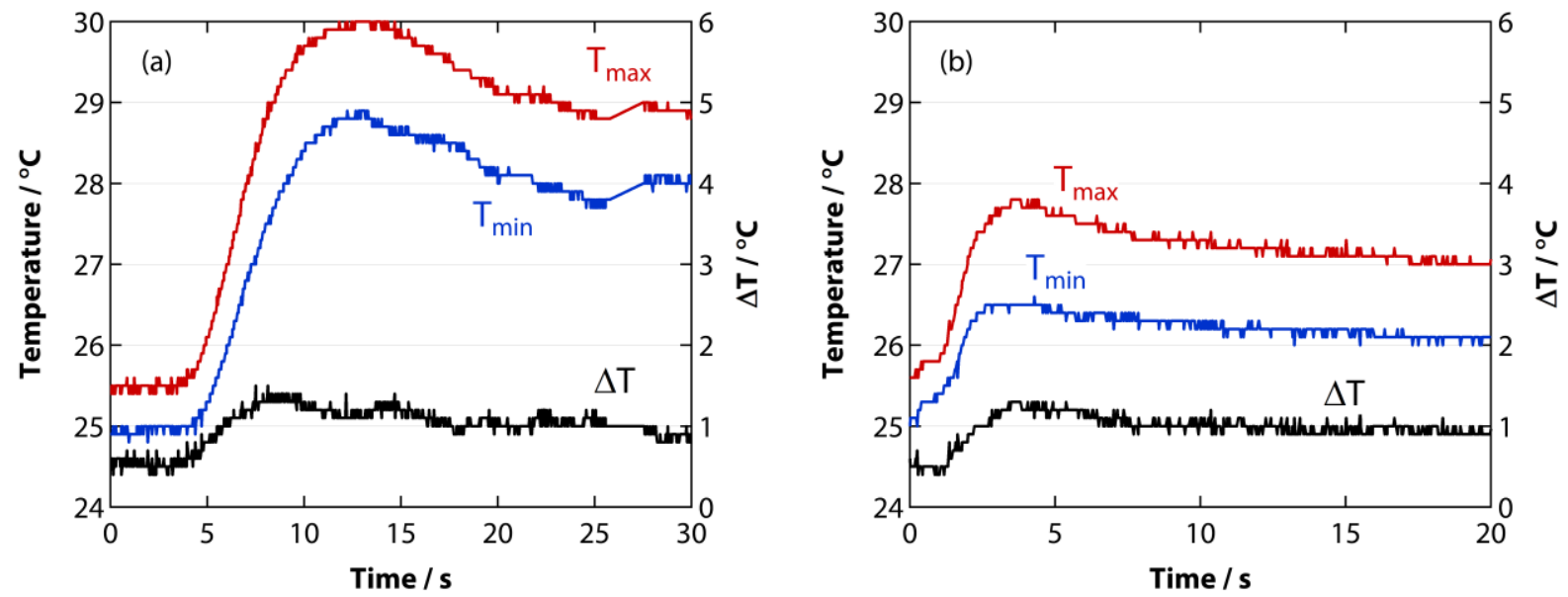

Figure 7. Temperature profiles of a $5 \mathrm{~cm} \times 5 \mathrm{~cm}$ GDE sample with $0.2 \mathrm{mg}$-Pt $\mathrm{cm}^{-2}$ nominal loading and $1 \mathrm{~cm}^{2} 50 \%$ defect using $0.4 \% \mathrm{H}_{2}$ and $0.2 \% \mathrm{O}_{2}$ in $\mathrm{N}_{2}$ at (a) 1500 and (b) $5000 \mathrm{sccm}$, respectively. 

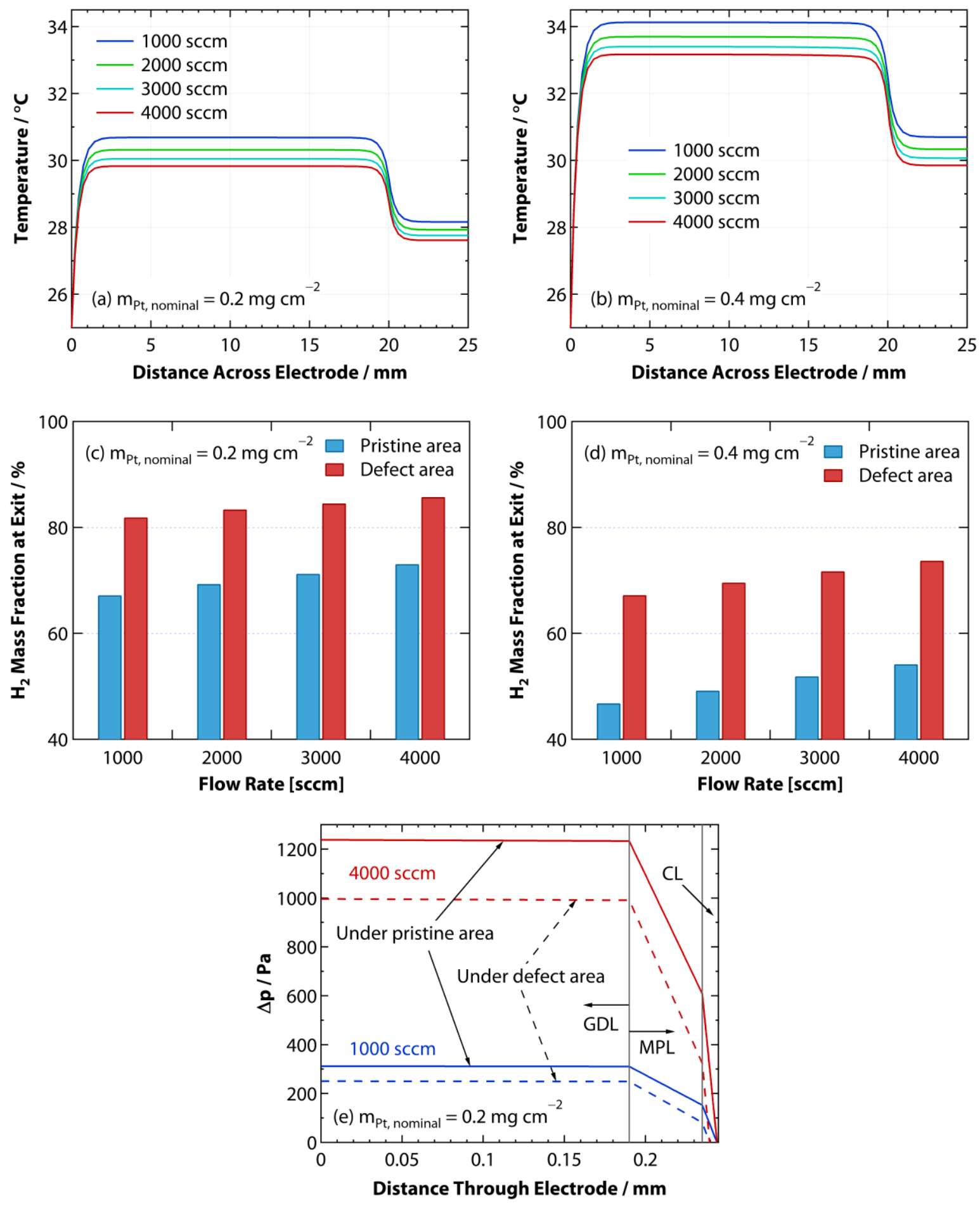

Figure 8. Simulated (a,b) temperature profiles, $(\mathrm{c}, \mathrm{d})$ extents of reaction, and (e) pressure drop through a $5 \mathrm{~cm} \times 5 \mathrm{~cm}$ GDE with $1 \mathrm{~cm}^{2} 50 \%$ defect with various gas-mixture flowrates using $0.4 \% \mathrm{H}_{2}$ and $0.2 \% \mathrm{O}_{2}$ in $\mathrm{N}_{2}$. The temperature profiles are from $\mathrm{CL}$ edge to defect center for loadings of (a) $0.2 \mathrm{mg}-\mathrm{Pt} \mathrm{cm}{ }^{-2}$ and (b) $0.4 \mathrm{mg}-\mathrm{Pt} \mathrm{cm} \mathrm{cm}^{-2}$, the extents of reaction are presented as the exit mass-fraction percentage of hydrogen for (c) $0.2 \mathrm{mg}-\mathrm{Pt} \mathrm{cm}{ }^{-2}$ and (d) $0.4 \mathrm{mg}-\mathrm{Pt} \mathrm{cm}{ }^{-2}$, and the pressure-drop data are for $0.2 \mathrm{mg}-\mathrm{Pt} \mathrm{cm}^{-2}$. 


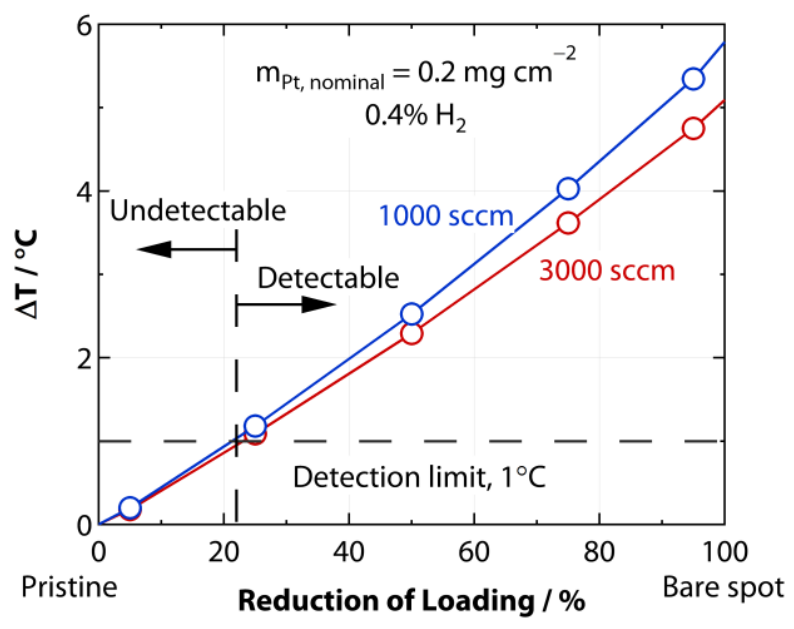

Figure 9. Temperature rise between the defect and non-defect area as a function of defect loading for a $1 \mathrm{~cm}^{2}$ defect at two different flowrates for a $5 \mathrm{~cm} \times 5 \mathrm{~cm}$ GDE sample with a $1 \mathrm{~cm}^{2}$ defect. 


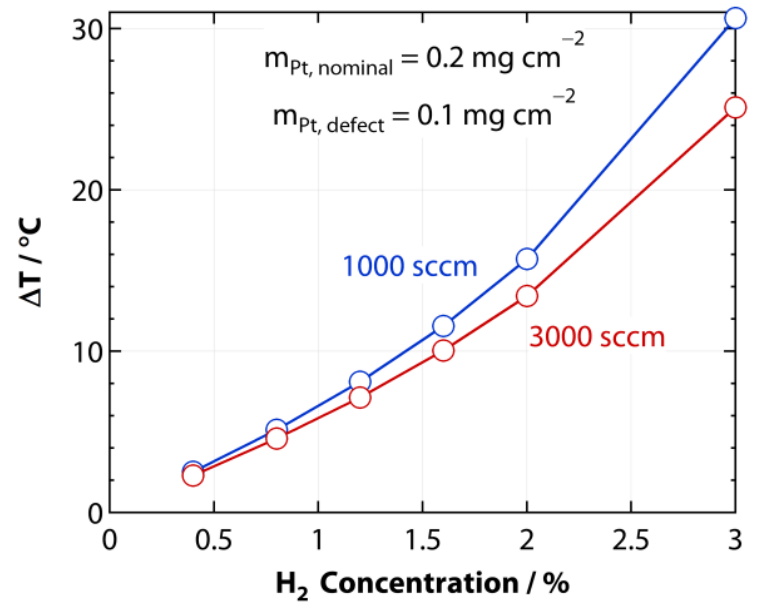

Figure 10. Temperature differential between the defect and non-defect (pristine) area as a function of hydrogen concentration for a $5 \mathrm{~cm} \times 5 \mathrm{~cm}$ GDE sample with a $1 \mathrm{~cm}^{2} 50 \%$ loading reduction defect at two different flowrates. 

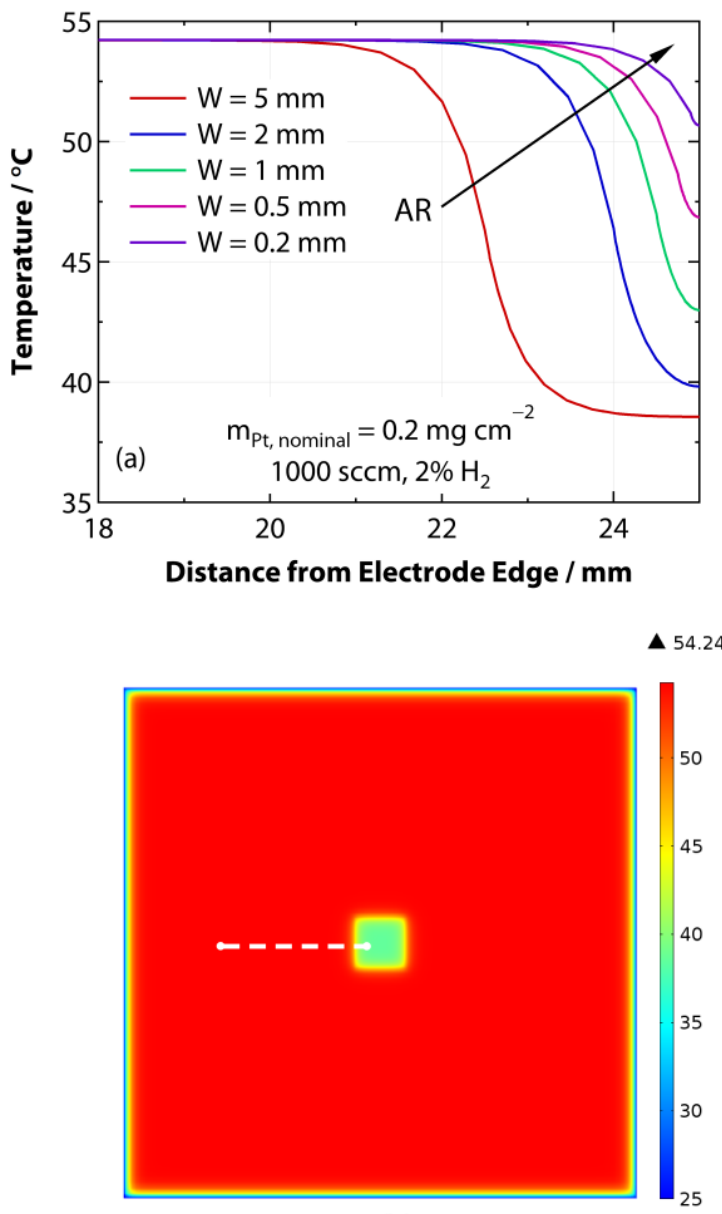

(b)

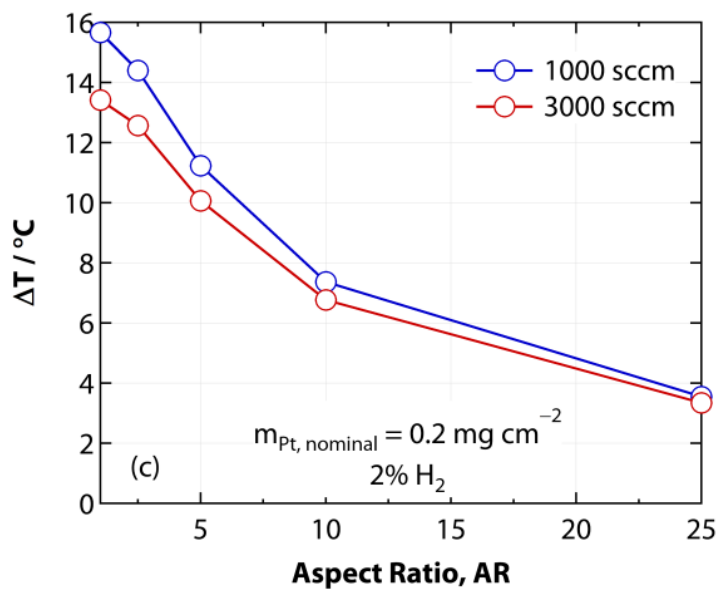

Figure 11. Modeling predictions for a gas mixture of $2 \% \mathrm{H}_{2}$ and $1 \% \mathrm{O}_{2}$ in $\mathrm{N}_{2}$, a variety of geometric aspect rations and flows. (a) Effect of geometric aspect ratio of the defect on the temperature profiles across the electrode along the white dashed line for a $50 \%$ loading and 0.5 $\mathrm{cm}$ wide defect. (b) Modeling results of thermographic image with geometric aspect ratio of 1. (c) Temperature differential between defect and non-defect area as a function of aspect ratio at two different flowrates. 


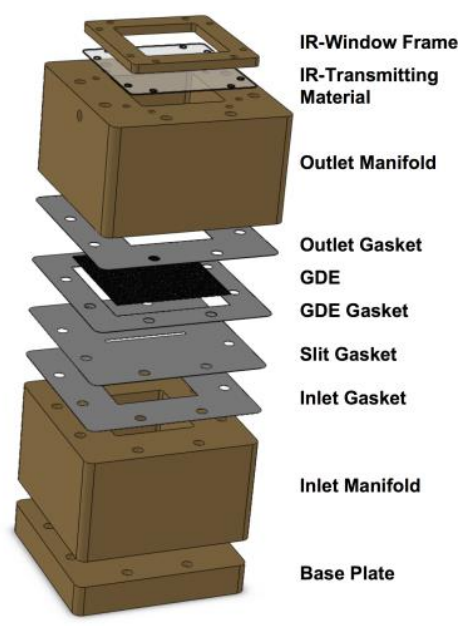

(a)
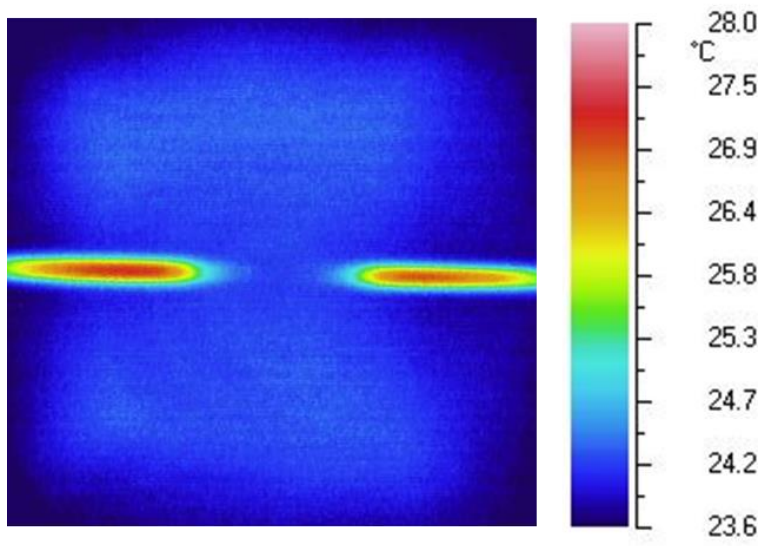

(b)

Figure 12. (a) Experimental configuration for line flow experiment using a slotted gasket. (b) Thermographic image of a $2 \mathrm{~cm}^{2}, 100 \%$ reduction, $0.2 \mathrm{mg}-\mathrm{Pt} \mathrm{cm} \mathrm{cm}^{-2}$ nominal loading sample at a flowrate of $3000 \mathrm{sccm}$ and hydrogen concentration of $0.4 \%$. 